\title{
Community
}

\section{EOS News}

https://doi.org/10.1515/aot-2019-0003

\section{EOS asked to keep photonics as key enabling technology (KET)}

The European Commission has published a proposed legislative package for a post-2020 multiannual financial framework (MFF) of $€ 1279$ billion for the years 2021-2027, including almost $€ 100$ billion for the Horizon Europe programme (the successor of H2020). In the current proposal for Horizon Europe, photonics no longer appears as a visible priority area.

The European Optical Society (EOS) has expressed its concern to the European Commission about diluting the position of photonics as a KET and the repercussions of doing so, e.g. the effects to SME. We urge each national optical society to take a stand and do everything in their power to keep the position of photonics as a KET.

\section{Co-operation agreements renewed with several societies}

EOS has renewed its co-operation agreements with the Taiwan Photonics Society (TPS), the Optical Society of Korea (OSK), and the Japan Society of Applied Physics (JSAP).

All EOS members are again able to receive the benefit of discounts in the partner society events until end of 2020 and submit papers to their conferences on the same terms as each society's members.

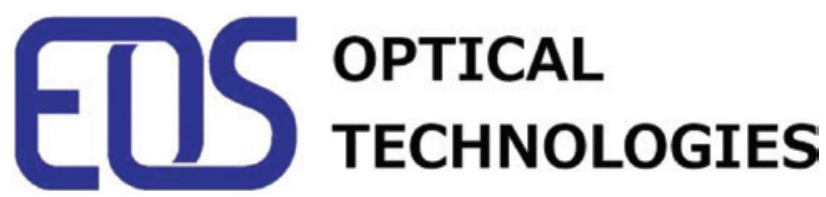

\section{Submission open for 5 th Optofluidics Conference}

The Conference on Optofluidics has now been organized for the fifth time under the umbrella of the World

www.degruyter.com/aot

(C) 2019 THOSS Media and De Gruyter of Photonics Congress, held June 24-27, 2019 in Munich, Germany, as part of the EOS Optical Technologies conferences.

Optofluidics emerged approximately 10 years ago aiming at the fusion of integrated optics with microfluidics. Since then, a wealth of new scientific principles and technologies have emerged. Through this conference, the latest developments in Optofluidics will be explored, serving as one of the main meeting points of the international optofluidics community.

Submission is now open, and submissions can be sent up to February 25, 2019. For submission to all conferences of the EOS Optical Technologies Congress you may use the following link: https://www.conftool.com/ wpc2019

\section{Important dates}

Submission deadline

February 25, 2019

Notification to authors

April 5, 2019

Pre-registration opens

March 2019

Deadline for presenter registration

April 30, 2019

Early bird deadline

May 31, 2019

Pre-registration closes

June 2019

All two-page abstracts submitted and presented at the conference will be added to the proceedings, published with EDP Sciences, in the Web of Conferences. The authors retain the copyright of their abstracts. The proceedings will be indexed in main data bases and become available online after the conference.

At least one author is requested to register for the meeting. Authors are kindly asked to read the submission guidelines and download the templates before starting the submission process.

\section{Chairs of the conference:}

Andreas Vasdekis, University of Idaho (USA) and Demetri Psaltis, École Polytechnique Fédérale de Lausanne (Switzerland)

\section{Topics}

- Photonics

fundamental linear and non-linear optics, lasers, sensors, microscopy, optical tweezers 
- Health and Biology

Single-cell and single-molecule methods, drug delivery, ultra-high throughput screening

- Imaging integration, time-stretching, image processing, big-data

- Handheld Devices mHealth, portable diagnostics

- Energy - Environment photobioreactors, biophysics, optofluidics of plants

- Transport optics, microfluidics, computational methods

- Micro-Fabrication prototyping, three-dimensional (3D) and four-dimensional (4D) particle generation, BioMEMS

- Hybrid Integration integrated optics [surface enhanced Raman scattering (SERS), waveguides, resonators], electronics, and applications

- Soft Matter liquid crystals, vesicle photonics

- Industry industrial applications, related technologies and products

\section{Plenary Speaker}

Hatice Altug, École polytechnique fédérale de Lausanne (EPFL), Switzerland

\section{Invited Speakers}

Anupam Sengupta, University of Luxembourg, Luxembourg Thomas F. Krauss, University of York, UK Ivan I Smalyukh, University of Colorado, Boulder, CO, USA Andrew deMello, ETH Zürich, Switzerland

Christophe Moser, EPFL, Switzerland

\section{Programme Committee}

Anders Kristensen, Technical University of Denmark, Denmark

Lynn Paterson, Herriot-Watt University, UK
David Erickson, Cornell University, UK

Holger Schmidt, University of California at Santa Cruz, CA, USA

Submission for the Manufacturing, Tolerancing, and Testing of Optical Systems will open January 10, 2019.

\section{EOS Co-sponsored Events}

7th International Conference on Photonics, Optics and Laser Technology

http://www.photoptics.org/Home.aspx

25-27 February 2019

Prague, Czech Republic

AOP2019, 4th International Conference on Applications of Optics and Photonics

www.aop2019.org

31 May-4 June 2019

Lisbon, Portugal

Optics and Photonics Days (OPD) 2019

https://www.photonics.fi/opd2018-2/

27-29 May 2019

Espoo, Finland

\section{New Emails for the EOS office}

Please note the new email addresses of the EOS office: firstname@europeanoptics.org

Elina Koistinen, EOS Executive Director: elina@europeanoptics.org

Tiina Romppanen, Finance Assistance and Memberships: tiina@europeanoptics.org

Hannnele Karppinen, Conference Manager: hannele@ europeanoptics.org 


\section{Community}

\section{Conference Notes}

\section{Preview: Laser World of Photonics 2019}

Munich, Germany, 23-27, June, 2019

The 'Laser Munich', as most visitors call this event, is one of the oldest (it began in 1973), largest (1290 exhibitors in 2017) and most popular (32 700 visitors in 2017) trade fairs for photonics worldwide. While the spin-off event in Shanghai overtook it in popularity with nearly 56000 people last year, Laser Munich is still a must-see in our community. Laser Munich is still a bi-annual event and consists of a large congress and a long list of additional events. A larger preview will be published in issue 3 of this journal.

\section{About the trade show}

It is a difficult challenge to give an overview of the trade show in just a few lines. In 2019 the show will extend over five halls on the Munich fair grounds. The main focus will be on lasers and optoelectronics (halls B2 and 3). In halls A2 and 3 one will find lasers and laser systems for production (engineering). Hall B1 will be dedicated to optics and manufacturing technology for optics, while smaller areas will be used for the presentation of imaging technology (A2), sensors and optical measurement technology (A2), biophotonics and medical engineering (B2), and optical information and communication technology (B3).

According to the fair ground map from Messe München, hall A1 will be dedicated to the congress. This will be an opportunity for trade show visitors to get a glimpse of the congress. The regular scientific program with its various conferences will be held in the co-located
International Congress Center ICM and requires a separate (and larger) entrance fee.

Those who want to save the money for the congress will find an extensive support program at the Laser fair. Arnold Mayer from Optech Consulting will present his 14th International Laser Marketplace, a half-day event covering market trends and delivering the most reliable analytical data of laser markets.

In several places in the halls there will be stages for so-called application panels. These are presentations from scientific and commercial experts grouped into topical sessions on various fields of photonics. In 2017 Laser Munich presented a startup area and some related events - there is a good chance this will be repeated in 2019.

\section{The World of Photonics Congress}

This scientific congress was split into a number of events from various organizers with a total of 4000 attendees and about 3000 lectures and presentations in 2017. Traditionally, it is hard to retain an overview of the events, and harder still to retain an overview of the complex schedule. The organizers are aware of the problem and have promised a clear conference structure for 2019.

They say: 'To depict all aspects of optical technologies, the conferences at the World of Photonics Congress are oriented to the research sector's close proximity to industry on the one hand and to photonics applications in the industrial and medical sectors on the other'. The following graph gives a rudimentary outline of the congress structure with its seven conferences. A more detailed preview will be given in issue 3 of Advanced Optical Technologies. A detailed overview of the 2017 event can be found at https://doi.org/10.1515/aot-2017-0038.

www.laser.de 


\section{STRUCTURE}

\section{World of Photonics Congress 2019}

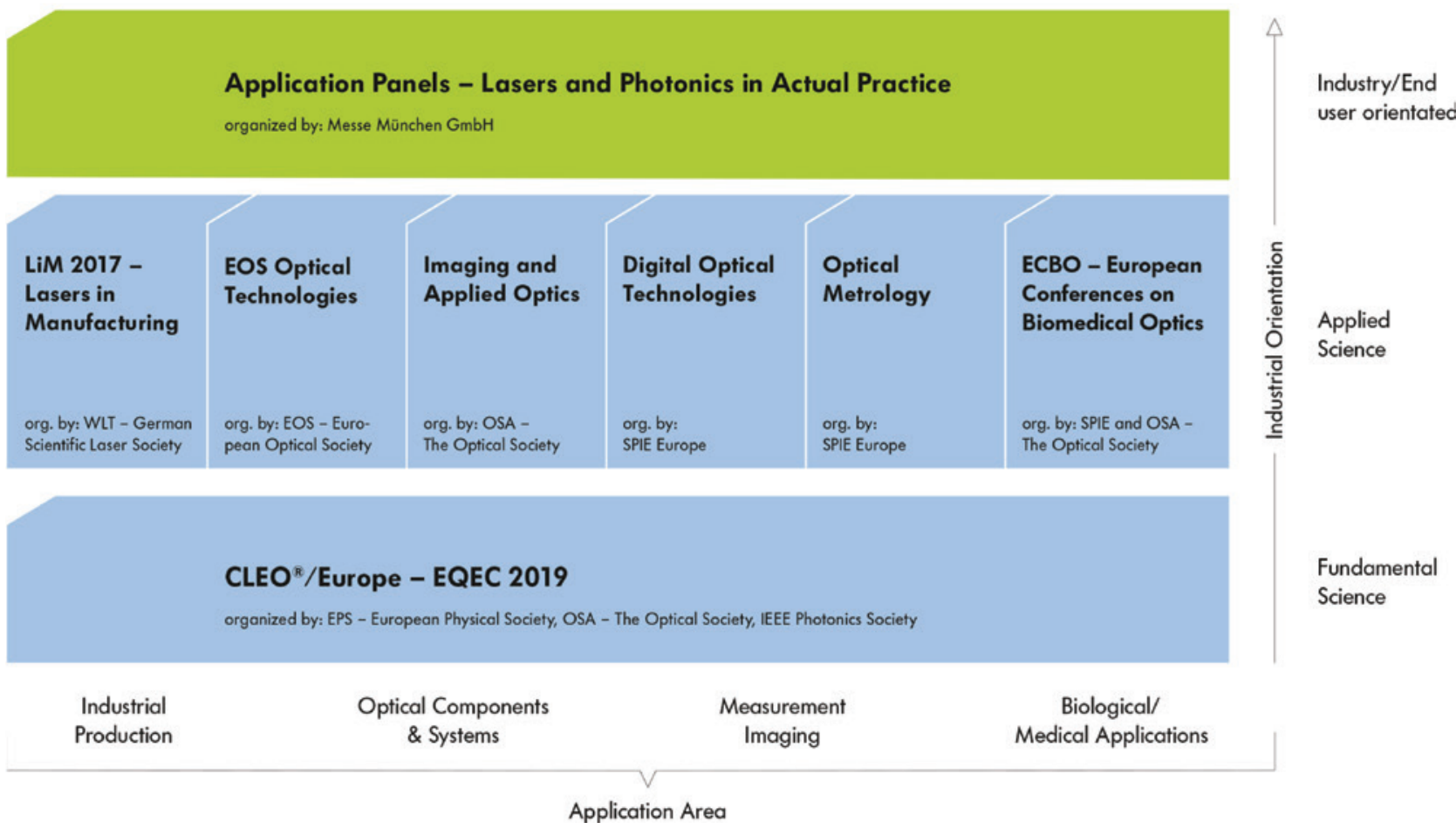

Structure of the World of Photonics Congress 2019 (Copyright: Messe München).

\section{Preview: UKP-Workshop 2019}

Aachen, Germany, 10-11, April, 2019

Specialists from laser development, process engineering and industry will meet in Aachen from April 10 to 11, 2019 for the '5th UKP-Workshop: Ultrafast Laser Technology', organized by the Fraunhofer Institute for Laser Technology ILT. Twenty speakers will inform the approximately 200 expected participants from Germany and abroad about the latest developments in USP laser beam sources and optical systems for ultrashort pulse (USP) laser technology.

The '5th UKP-Workshop: Ultrafast Laser Technology' will focus on new systems for engineering solutions for increasing the productivity of processes in UPS laser material processing. In addition to the basics of USP technology, 20 speakers from different countries will address current issues: How can large average output powers of USP laser beam sources be realized and efficiently implemented in the corresponding machining processes? Which system-technical solution approaches and beam shaping concepts are available to distribute the high average power on the workpiece surface and which new possibilities of material processing result from this? What do users have to consider with regard to processing technology? And what challenges must be mastered in system technology?

In addition to the new developments and trends in USP technology, new findings on the generation of X-rays will also be presented. Furthermore, experts will present the latest laser-based applications and processing methods that extend the limits of existing technologies in terms of process speed, quality, and material range.

www.ultrafast-laser.com. 


\section{Community}

\section{Conference Calendar}

2019

\section{January}

SPIE Photonics West

San Francisco, CA, USA

2-7 February 2019

Exhibition: 5-7 February 2019

http://spie.org/pw

\section{February}

SPIE Advanced Lithography

San Jose, CA, USA

24-28 February 2019

https://spie.org/advanced-lithography

\section{March}

OFC

San Diego, CA, USA

3-7 March 2019

www.ofcconference.org

\section{April}

\section{UKP-Workshop}

Aachen, Germany

10-11 April 2019

www.ultrakurzpulslaser.de

OSA Biophotonics Congress: Optics in the Life Sciences Tuczon, AR, USA

14-17 April 2019

www.osa.org/Meetings/OSA_Meetings/OSA_Biophotonics_Congress

\section{May}

\section{CLEO}

San Jose, CA, USA

5-10 May 2019

www.cleoconference.org

\section{June}

Optical Interference Coatings

Santa Ana Pueblo, NM, USA

2-7 June 2019

www.osa.org/Meetings/Topical_Meetings/Optical_Interference_ Coatings

\section{OSA Optical Design and Fabrication Congress}

Washington, DC, USA

10-12 June 2019

www.osa.org/Meetings/OSA_Meetings/Optical_Design_and_Fabrication

120. Annual Meeting DGaO

Darmstadt, Germany

13-16 June 2019

www.dgao.de/de/jahrestagung

LASER World of Photonics

Munich, Germany

24-27 June 2019

www.laser.de

\section{World of Photonics Congress}

European Conferences on Biomedical Optics (ECBO)

Lasers in Manufacturing (LiM)

EOS Optical Technologies

Imaging and Applied Optics (OSA)

Digital Optical Technologies (SPIE)

Optical Metrology (SPIE)

CLEO/EQEC Europe

Munich, Germany

23-27 June 2019

www.photonics-congress.com

\section{July}

2019 International Conference on Numerical Simulation of Optoelectronic Devices (NUSOD)

Ottawa, ON, Canada

8-12 July 2019

Abstract Submission Date: March 15, 2019

www.nusod.org/2019/

\section{OSA Advanced Photonics Congress}

Burlingame, CA, USA

29 July-1 August

www.osa.org/en-us/meetings/osa_meetings/advanced_photonics_ congress/

\section{September}

Frontiers in Optics: the 103rd OSA Annual Meeting and Exhibit/ Laser Science Conference

Washington, DC, USA

16-19 September 2019

www.osa.org/Meetings/Global_Calendar/Events/Frontiers_in_ Optics_the_103rd_OSA_Annual_Meeting 
2019 European Conference on Optical Communications (ECOC) Dublin, Ireland

22-26 September 2019

Abstract Submission Date: April 19, 2019

www.ecoc2019.org/

\section{OSA Laser Congress}

Laser Applications Conference

Advanced Solid State Lasers Conference

Vienna, Austria

29 September-3 October 2019

www.osa.org/Meetings/Global_Calendar/Events/Advanced_Solid_ State_Lasers_Conference (1)

2019 IEEE Photonics Conference (IPC)

San Antonio, TX, USA

29 September-3 October 2019

Abstract Submission Date: May 20, 2019

http://ieee-ipc.org/
SPIE Optifab

Rochester, NY, USA

14-17 October 2019

https://spie.org/conferences-and-exhibitions/optifab

\section{November}

2019 24th Microoptics Conference (MOC) Toyama, Japan

17-20 November 2019

www.moc2019.com/

\section{0}

2020 Optical Fiber Communications Conference and Exhibition (OFC)

San Diego, CA, USA

8-12 March 2020

www.ofcconference.org

\section{October}

V2019 - Vakuum \& Plasma

Dresden, Germany

8-10 October 2019

www.v-workshopwoche.net 